Pothen, L.S. and Ramalingam, S. (2018). "Applicability of value stream mapping and work sampling in an Industrial Project in India." In: Proc. 26 $6^{\text {th }}$ Annual Conference of the International. Group for Lean Construction (IGLC), González, V.A. (ed.), Chennai, India, pp. 516-526. DOI: doi.org/10.24928/2018/0263. Available at: www.iglc.net.

\title{
APPLICABILITY OF VALUE STREAM MAPPING AND WORK SAMPLING IN AN INDUSTRIAL PROJECT IN INDIA
}

\author{
Lavina Susan Pothen ${ }^{1}$ and Shobha Ramalingam ${ }^{2}$
}

\begin{abstract}
Poor productivity and inefficiencies in the production process are alarming issues in the construction industry that also erode the value proposition of projects. Value Stream Mapping (VSM) and Work Sampling (WS) are two important techniques in the 'Lean' philosophy that aim at reducing and minimizing 'waste' in the life cycle process of activities and thereby aide in maximizing productivity. In this paper, we discuss the implementation challenges and benefits of these two techniques in an industrial project in India through an action-based research methodology. While VSM was adopted for Vacuum Dewatering Concrete Flooring works, tour based WS was done for block-work activity. VSM helped to visualize the entire process and reduce time overrun by 2.5 days. Alternative materials were cost estimated and compared to reduce cost overrun. The WS technique helped the contractor to assess the productivity rate and identify reasons for below average productivity. Subsequent corrective action plans and recommendations led to reduce non-value added wastes and improve performance. This study lays a foundation for practitioners to systematically adopt these lean techniques in practice and thereby optimize the process, reduce wastes and enhance productivity.
\end{abstract}

\section{KEYWORDS}

Value Stream Mapping, Work Sampling, Lean Principles, Process Optimization, Industrial Project.

\section{INTRODUCTION}

In order to stay competitive, firms in the Architecture Engineering and Construction industry will have to constantly review their process and continuously improve their performance. Construction industry is inherently plagued by poor productivity. A

${ }^{1}$ Executive - Design, Oberoi Realty, Mumbai, Maharashtra, India. +91 9008420361, lavina27@gmail.com (Author for Correspondence)

${ }^{2}$ Assistant Professor, National Institute of Construction Management and Research (NICMAR), Pune, Maharashtra, India. 02066859122, sramalingam@ nicmar.ac.in 
McKinsey study reports that over the past 20 years, productivity has increased by only $1 \%$ in construction (McKinsey TR, 2017). Lean methods and techniques aim at providing viable solutions to this alarming concern in the industry by identifying and eliminating waste in the process that do not create value for the product, the process and the end customer (Ingle and Waghmare, 2015) and thereby improving productivity. In this study we focus on two lean tools, namely, Value Stream Mapping (VSM) and Work Sampling (WS) and provide a brief overview of the same below:

VSM is a lean tool to visually map the process and identify both the value adding and the non-value adding activities (wastes) in the current state of the production process (Tapping et al., 2002). Subsequently, a future state map is generated by eliminating wastes or by finding alternative solutions through kaizen efforts to optimize the process. The new implemented process is then observed to aim for the next higher level of productivity improvement. Howell and Ballard (1998) contend that a value stream map can be a comprehensive model for a project to reveal issues that are hidden in current approaches and raises the possibility of maximising performance at the project level. VSM method follows a 5-stage process (Rother and Shook, 1999) that includes: selection of a product family, creating a current state map, identifying waste and developing a future state map, proposing an action plan and implementation of the action plan.

WS is yet another lean tool that can administer the management of site resources, time and labour. In WS, a series of instantaneous observations as 'snap shots' of work in progress is taken randomly over a period of time (Jenkins and Orth, 2003) to measure productivity. This method provides information on the amount of time workers spend performing productive, supportive, and non-productive work. This technique thus provides valuable information regarding areas of low productivity, which in turn can inform for the needed corrective action (Thomas and Napolitan, 1999). Work sampling was shown to provide important information about the characteristics of delays (Thomas and Daily 1983).

In summary, VSM and WS are both elemental time studies. While VSM maps the time taken to perform a task and WS describes how much time is spent on the task productively (or non-productively). The strengths of these two lean techniques, however, interest us to explore the organizational inefficiencies present at construction sites, particularly in India, where the lean principles and methods are still in its nascent stage. To this end, a study was undertaken to understand the implementation of VSM and WS in an industrial project and assess its impact with respect to cost, time and overall productivity.

\section{METHODOLOGY}

\section{RESEARCH SETTING}

$\mathrm{ABC}$ is a leading construction company in India. Over the years, ABC firm has proactively taken strategic decisions to implement lean principles and techniques with the support of Lean consultants. The firm strives to achieve the following Lean goals: a) Advance Constraint finding and resolution to complete the project as per schedule, b) 
Conduct productivity study for future plan and to set up standard for ongoing works, c) Creation of better work environment for everyone, d) Conduct time motion study to remove any kind of non-value adding waste, e) Commitment tracking from civil contractors as per execution phase schedule and f) Root cause resolution to streamline the execution activity.

ABC firm has three business verticals, namely, Construction Materials, Construction Contract and Real Estate. The study was conducted on an Industrial expansion project that falls under the Construction Contract vertical, spread over a plot area of 300 acres. The project scope consisted of infrastructure facilities like internal roadways, power infrastructure and units like manufacturing plants (5\#), warehouses, utility building and switchyard. The manufacturing plants in the facility have an area of approximately 20,000 square meters each. The study was conducted on specific construction activities executed in manufacturing plant-4 for VSM analysis and in manufacturing plant-1 for WS study.

\section{DATA COLLECTION AND IMPLEMENTATION METHODS}

Data was collected from a single site and on specific activities in a project through an action-based research approach. 'Action Research', coined foremost by Kurt Lewin, is a methodology that can be undertaken by a focused team of practitioners/researchers to solve an immediate practical problem in a real setting using data feedback system in a cyclical 5-stage process that includes: a) diagnosing (identification of primary problem), b) action planning (establishing targets for change using a guided theoretical or empirical framework), c) action taking (implementing planned actions through intervention of practitioners/researchers), d) evaluating (outcomes) and e) specifying learning (through reflection) (Stringer, 1999; Baskerville, 1997).

The first author spent two months on the site and was part of a team that explored the implementation of VSM for vacuum dewatering concrete flooring (VDF) activity in the manufacturing plant-4 of the facility and WS for block-work activity in manufacturing plant-1. The methodology adopted is explained below.

\section{VALUE STREAM MAPPING}

VDF was a critical activity that was scheduled to be executed on site. It was diagnosed and decided to map this activity using VSM technique. The objective was to optimize cost and time in the VDF execution process. VDF in Manufacturing plant-4 had FM2 (FM-Free Movement) class of flooring suitable for high abrasion and heavy traffic movement as per recommendations from the technical report of concrete industrial ground floors by the concrete society (TR34, Concrete Society). The first author and a project manager took turns to visit the site as per a scheduled plan in May 2017 and observed the process step-by-step in order to map the entire sequence of activities (work flow). The process was captured through photographs, videos and hand-written notes. The sequence was further transcribed and documented chronologically. The captured photographs, videos and the transcribed texts were analyzed the next day. With the collected data, a flow chart was prepared that depicted the entire process and a current state map of the activity was created. Subsequently, planning the next action step, a 
committee comprising of a team of experts including in-house experienced contractors, site engineers, concrete technicians and the project manager analyzed the sequence of activities to identify wastes in the process through active brainstorming sessions (kaizen efforts). Alternative methods and materials were suggested to overcome cost and time over-run. Based on recommendations of the committee, the future state map for the activity sequence was planned and implemented on site. The findings are explained in the subsequent section.

\section{WORK SAMPLING}

Four activities were identified by the firm for work sampling. These included:

- PEB Erection of Primary Members in Plant 1.

- PEB Erection of Secondary Members in Plant 1.

- PEB Roof Liner of Plant 1.

- PEB Block-work of Plant 1.

Tour based work sampling was conducted for the four activities in Plant 1 . The activity was observed and diagnosed for a period of 30 days. Planning the next action plan, the first author stayed on site from 9 am to 5 pm, for a month in June 2017 and recorded the activities manually in an observation table pre-designed in the firm under 3 categories - Value Added activity (VA), Non-Value Added but Necessary activity (NVAN) and Non-Value Added activity (NVA). The work sampling information was therefore manually recorded on worksheets and the data was imported into a Microsoft Excel spreadsheet. Pie-charts were generated to illustrate time spent by job site workers on the identified categories. As a policy decision, the firm decided to take up activities for further improvement whose NVA was above $20 \%$, which meant the labour productivity for those activities were below average. After reviewing the data collected, it was found that the block-work activity alone fell under this category. For the remaining three activities, the contractor was operating at above average productivity level and hence, out of the 4 activities, the block-work activity was taken up for further improvement. The findings and recommendations to reduce the NVA in the block-work activity are discussed in the subsequent section.

\section{FINDINGS}

Discussed below are the consolidated findings from the VSM and WS implementation process on the selected activities in the project.

\section{VSM}

The floor area of manufacturing plant-4 was $140 \mathrm{~m} \mathrm{X} 160 \mathrm{~m}$. For casting of the floor, surface preparation was done initially for an area of 2160 sq.m $(60 \mathrm{~m}$ X 36m). The floor was divided into equal sized bays, each spanning $60 \mathrm{~m}$ by $4.5 \mathrm{~m}$. From the documented data, the time taken for each activity was identified and cross-checked with the project team members and the contractors to foremost prepare the current state map. According to the sequence steps and activity times, the process of VDF took 27 days to complete. 
Each activity step was subsequently micro-analysed during the brainstorming session. While most of the activities required the time as planned, channel fixing and transferring of the reinforcement bars to the site required 2.5 days which delayed further execution. Experts identified this as an activity not necessarily required to be in the sequence process and therefore tried to improvise this particular step by bringing it out of the main flow. Thus, it was proposed that the reinforcement mesh (which was not dependent on the earlier activity, metal rolling, in the sequence flow) be prepared earlier and stored at a location closer to where concreting would take place, which in turn would save time for the transportation of the mesh. This reduced the entire process time for the activity by 2.5 days and the new cycle required 24.5 days (noted as 25 through approximation) to complete the VDF flooring process. This decision was implemented on the site during the action taking phase. This also saved time for the execution team. Figure 1 graphically depicts the current state and the future state map of VDF activity. The red rectangular box shows the areas with Kaizen burst situations. 


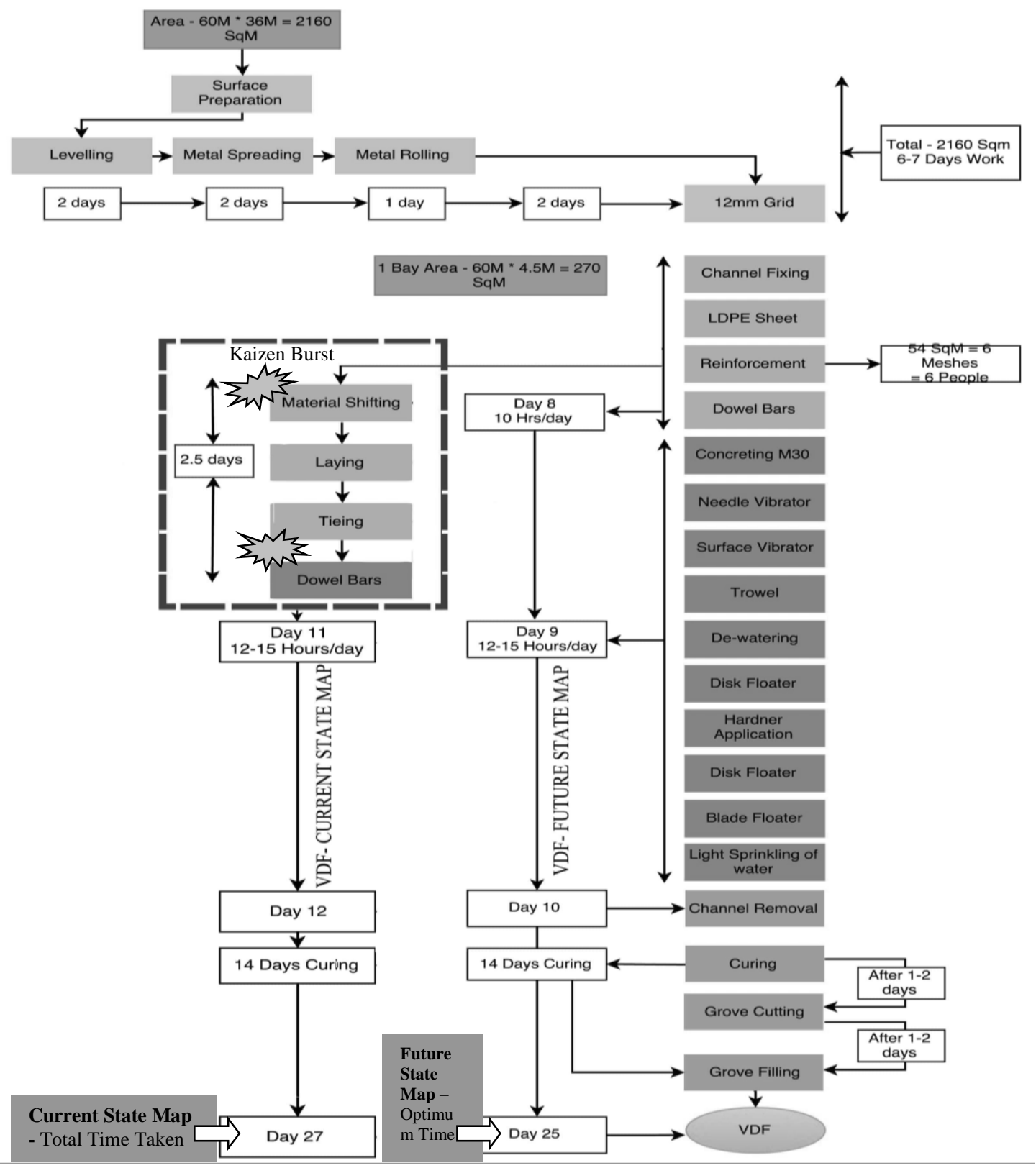

Figure 1: VSM and the Current and Future State Map of VDF activity

Value steam mapping helped in visualizing the entire work flow and identifying areas of improvement to optimize the schedule.

Figure 2 shows some of the photographs taken on site after implementation of the recommendations. 


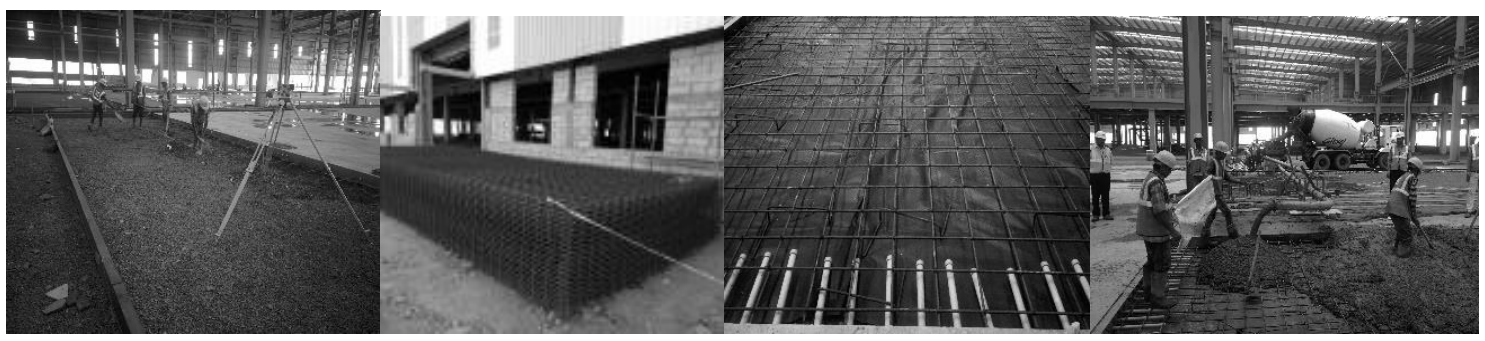

Figure 2: (a) Surface Levelling, (b) Reinforcement Mesh prepared in advanced, (c) LDPE Sheet and Reinforcement Mesh., (d) Concreting

Once the process in the future state map was applied in real time the following observations, recommendations and action plans were suggested in the evaluation and learning phase to further improve the activity and optimize the process with respect to time and safety as shown in Table 1 below:

Table 1: Recommendations and action plan for Vacuum Dewatered Flooring

\begin{tabular}{l}
\hline Observation \\
\hline Manpower and material \\
shortage as resource \\
availability. \\
In an ideal situation for the \\
VDF process, alternative \\
bays of flooring ( $60 \mathrm{~m} X 4.5 \mathrm{~m}$ \\
each) should be cast at site, \\
but due to manpower \\
shortage only one bay of $60 \mathrm{~m}$ \\
$X 4.5 \mathrm{~m}$ was cast in a day for \\
this project. \\
During the application of the \\
hardener on the bay, the \\
labourers at site were not \\
wearing safety goggles.
\end{tabular}

The traditional VDF process gave a tolerance of $3 \mathrm{~mm}$ $5 \mathrm{~mm}$.
Reinforcement mesh took up to 2 days for preparation.

Recommendation

Contractor should ensure that mobilization of resources is done prior to the activity. There is a need for more manpower to utilize the mesh that is already binded at site prior to the start of the activity.

Some people are sensitive to resins, hardeners, vapour etc. Therefore, it is advisable to use hand gloves/goggles and suitable protective clothing during the application of hardener on the bay.

Concrete floors can be constructed by using cutting edge technology of laying floors with Laser Screed (Small line Laser Screed machine, keeping in mind the scale of the project). A tolerance of $1 \mathrm{~mm}$ was achieved through this process.

Steel fibre reinforced concrete can be used as an
The labourers to be provided with suitable clothing and the supervisor at site should ensure they use it while they are at work.

The contractor should contact specialized agencies who use state-of-the-art machinery for laying the Industrial Floors. In most of the cases they would recommend Steel fiber reinforced concrete as an alternate to traditional mesh reinforcement. 
alternate to traditional mesh reinforcement.

Delay in Concrete Supply for the process of concreting at site.

\begin{abstract}
$A B C$ Firm has an in-house RMC plant. If the in-house concrete supply gets delayed, due to any reasons, then material preplanning should be done, or material should be catered by external agency
\end{abstract}

During the signing off stage the management team should ensure there is abundant supply of concrete for the activity to be conducted.

A techno-commercial comparison was done with alternate materials for cost and quality optimization that included comparison between reinforcement mesh Vs steel fibres Vs glass fibres for VDF flooring as shown in Table 2 below:

Table 2: Comparison of alternate VDF flooring materials

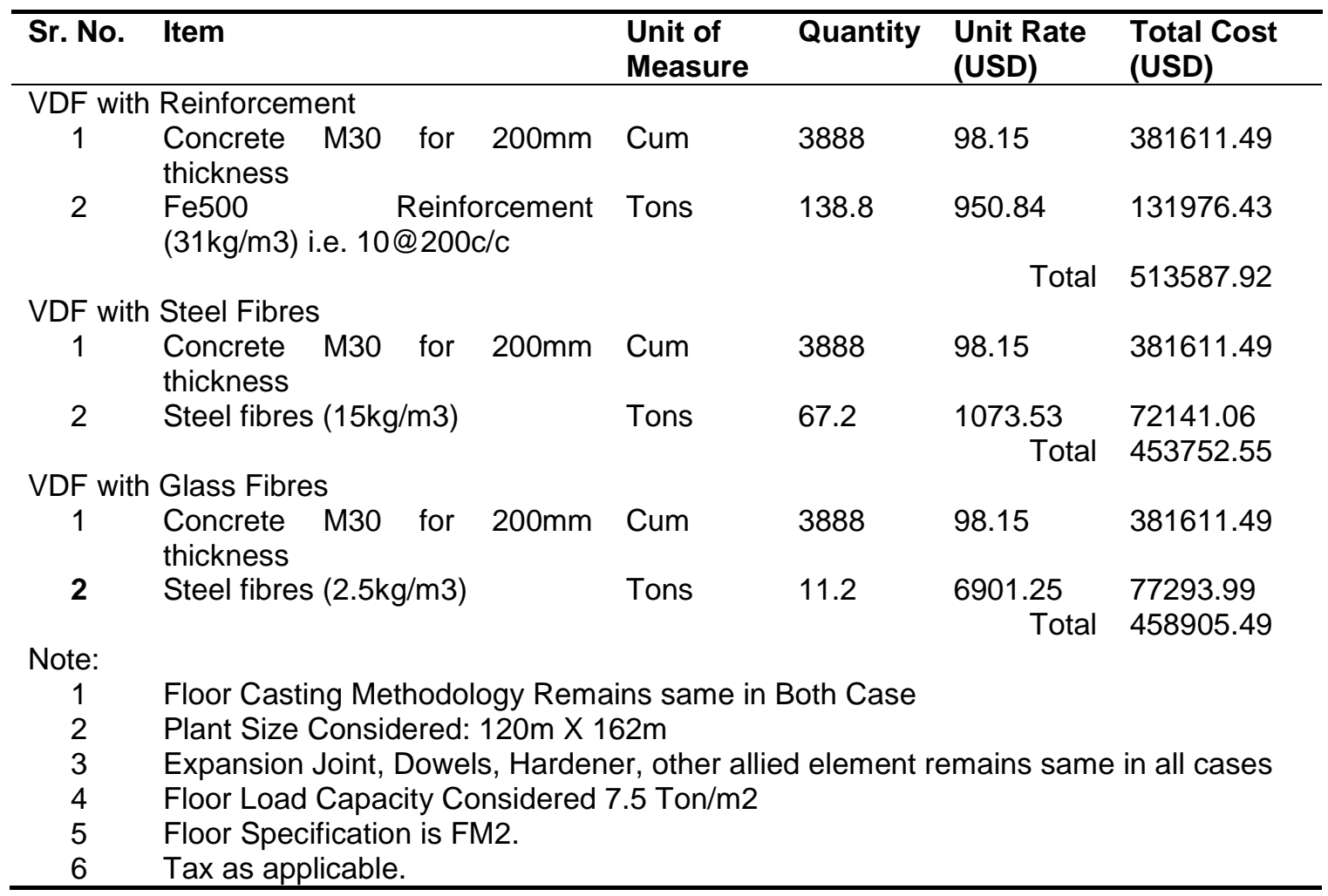

\section{WS}

Tour based work sampling was conducted at random time periods during the day for a period of one month during the action taking phase. The job site workers were not made aware of this study, to avoid possible hawthorn effect. The observations through tour sampling of PEB block work at plant-1, was initially noted under VA, NVA and NVAN categories in the standardized template of the firm as shown in the Figure 3 below. 


\begin{tabular}{|c|c|c|c|c|c|c|c|c|c|c|c|c|}
\hline \multirow[b]{2}{*}{ 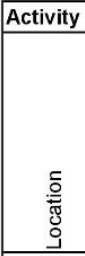 } & \multicolumn{2}{|c|}{ Blockwork at Plant-1 } & \multicolumn{4}{|c|}{ VA } & \multicolumn{3}{|c|}{ NVAN } & \multicolumn{3}{|c|}{ NVA } \\
\hline & $\frac{\mathscr{\varpi}}{\Delta ّ}$ & 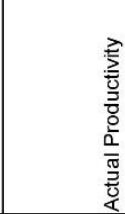 & 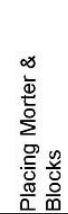 & 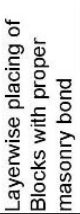 & 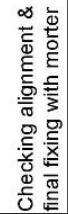 & $\begin{array}{l}\frac{m}{0} \\
\overline{0} \\
\end{array}$ & 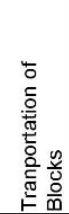 & 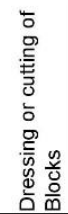 & $\begin{array}{l}\frac{\varphi}{\omega} \\
\overline{0}\end{array}$ & 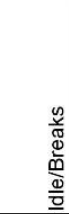 & 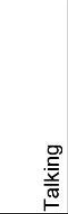 & $\begin{array}{l}\frac{\omega}{\omega} \\
\overline{ \pm} \\
0\end{array}$ \\
\hline \multirow{21}{*}{ 京 } & 02-May-17 & $200 \mathrm{sqm} /$ day & - & - & - & - & 3 & 2 & - & 2 & - & - \\
\hline & 03-May-17 & & - & - & - & - & 3 & 2 & - & 1 & - & - \\
\hline & 04-May-17 & & 1 & - & 1 & - & 1 & 1 & - & 4 & - & - \\
\hline & 05-May-17 & & 2 & & 1 & & 2 & & & & 2 & \\
\hline & 06-May-17 & & - & - & - & - & - & - & - & - & - & - \\
\hline & 08-May-17 & & 2 & 2 & & & 2 & 1 & & & 3 & \\
\hline & 09-May-17 & & 2 & 2 & 2 & & & 1 & & 4 & 2 & \\
\hline & 10-May-17 & & 2 & 2 & 2 & & 2 & 1 & & 1 & 2 & \\
\hline & 11-May-17 & & 2 & 2 & & & & 2 & & 1 & & 1 \\
\hline & 12-May-17 & & 4 & 2 & & & 5 & 2 & & 2 & & 2 \\
\hline & 13-May-17 & & 4 & 2 & & & 4 & 1 & & 1 & & \\
\hline & 15-May-17 & & 2 & 2 & & & 2 & & & 2 & & \\
\hline & 24-May-17 & & 1 & & & & & 1 & & & & 1 \\
\hline & 25-May-17 & & 1 & 1 & & & 4 & 2 & & 2 & & 2 \\
\hline & 26-May-17 & & 1 & 1 & & & 4 & 1 & & & & \\
\hline & 27-May-17 & & 1 & 1 & & & 3 & & & 2 & & \\
\hline & 29-May-17 & & 1 & 1 & & & & 1 & & & & 1 \\
\hline & 30-May-17 & & 1 & 1 & & & 5 & 3 & & 2 & & 2 \\
\hline & Sum & & 27 & 19 & 6 & 0 & 40 & 21 & 0 & 24 & 9 & 9 \\
\hline & Total & & \multicolumn{4}{|c|}{52} & \multicolumn{3}{|c|}{61} & \multicolumn{3}{|c|}{42} \\
\hline & $\%$ Contribution & & \multicolumn{4}{|c|}{33.5483871} & \multicolumn{3}{|c|}{39.35483871} & \multicolumn{3}{|c|}{27.09677419} \\
\hline
\end{tabular}

Figure 3: Work sampling data sheet for block-work at plant-1

Data was analysed through pie-charts to understand the percentage contribution of VA, NVAN and NVA in overall productivity. Table 3 below lists some of the identified activities in each category.

Table 3: VA, NVA and NVAN activities in Block-work

\begin{tabular}{|c|c|c|}
\hline Value adding activity (VA) & $\begin{array}{l}\text { Non-Value adding but } \\
\text { necessary activity (NVAN) }\end{array}$ & $\begin{array}{l}\text { Non-Value adding activity } \\
\text { (NVA) }\end{array}$ \\
\hline Placing Mortar \& Blocks & Transportation of Blocks & Idle time, Breaks \\
\hline $\begin{array}{l}\text { Layer wise placing of Blocks } \\
\text { with proper masonry bond }\end{array}$ & Dressing or cutting of Blocks & Talking \\
\hline $\begin{array}{l}\text { Checking alignment \& final } \\
\text { fixing with mortar }\end{array}$ & $\begin{array}{l}\text { Others including inspection, } \\
\text { approval }\end{array}$ & Others \\
\hline
\end{tabular}

Work sampling technique helped to identify the non-productive time and minimize it during the evaluation phase. Figure 4 below shows the percentage contribution of the activities using Pie-charts. 4(a) shows the consolidated percentage of VA (34\%), NVA (27\%) and NVAN (39\%) activities, 4(b) shows the percentage contribution of each activity in NVAN, and 4(c) shows the percentage contribution of NVA. From the study, it was observed that the most common NVA was idle time and that was caused due to lack of effective supervision. 


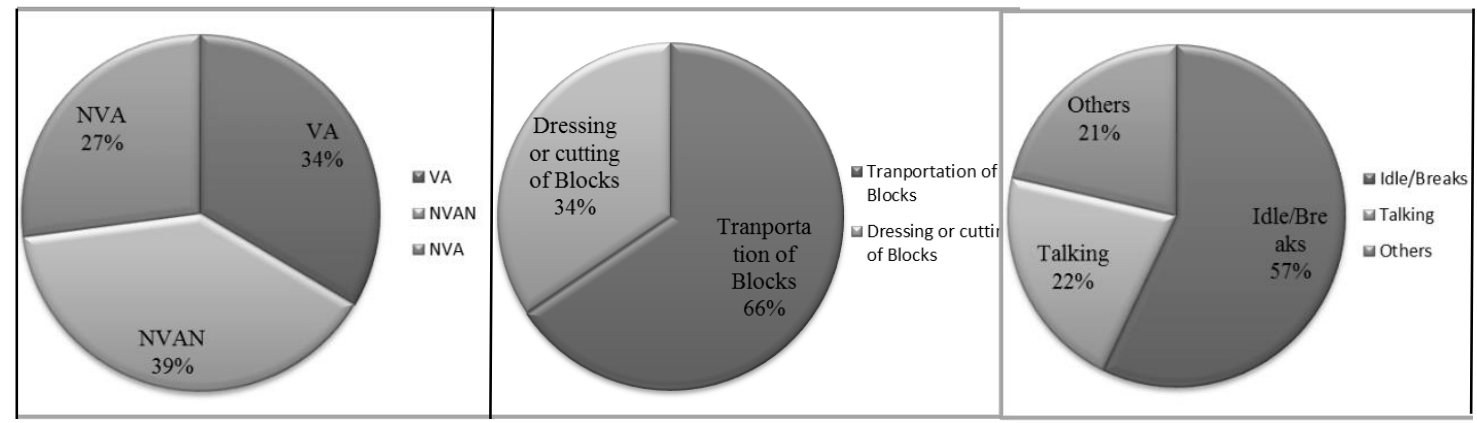

Figure 4: (a) Consolidated Percentage Contribution of Work, (b) Percentage Contribution of Work (NVAN), (c) Percentage Contribution of Work (NVA)

Based on the analysis, further recommendation and action plan were provided during the learning phase for improving productivity as shown in Table 4 below

Table 4: Recommendations/action plan to improve productivity of block-work

Recommendation

Action Plan

Proper guidance should be given to the job

site workers during the execution of an activity.

Tool box meetings can be conducted every day to make the workers aware of productive time waste impact.

Time wastage can be reduced by proper supervision.

Proper supervision should be conducted to increase productivity by improving value added time for the specific activity.

Work front availability must due to completion of predecessor activity.

Proper planning of work must be executed in the job site. Provide number of skilled laborers to avoid delay in work.

\section{CONCLUSION}

The objective of the study was to understand the current scenario of on-site and labour productivity in a construction project and to analyse the benefits through the implementation of Lean techniques including VSM and WS. Value stream mapping technique for VDF proved to be beneficial to visually map the process and optimize the operation with respect to cost and time. In specific, it helped to measure the time taken for supporting activities such as channel fixing and transporting of wire mesh and adopt alternative method to optimize the process. Similarly, Work sampling helped to identify and reduce/eliminate non-productive time spent by workers and allowed the contractor to improve the productivity of block-work activity above average level. Thus, we contend that by adopting similar approaches, project managers will be able to take key decisions to enhance productivity and optimize performance. However, the study offers insight from a single project and therefore suffers from limitations for a broader and comprehensive generalize-ability. Future studies could also explore the combined effects of these lean tools in construction projects as prevalent in other sectors, such as for 
instance, Barnett et al. (2015) adopts work sampling to value stream map an activity in healthcare domain for process improvement.

\section{ACKNOWLEDGEMENT}

The authors thank ABC Firm for their support and guidance throughout the study.

\section{REFERENCES}

Baskerville, R. (1997) Distinguishing action research from participative case studies, Journal of Systems and Information Technology, 1(1), 25-45.

Barnett, A.E., Singer, J, Ray, A, Fussner, J and Tarr, R (2015) A Work-sampling Study to Value Stream Map the Door to Door Process, Circulation, AHA Journal, 132(3).

Howel, G. and Ballard, G. (1998) Implementation lean construction - Understanding and action. In Proceedings of the IGLC' 98. Guaruja, Brazil.

Ingle, A. And Waghmare, A, P. (2015) Advances in Construction: Lean Construction for Productivity enhancement and waste minimization, International Journal of Engineering and Applied Sciences, 2 (11)

Jenkins, J. and Orth, D. (2003) Productivity Improvement through Work Sampling. AACE International, Transactions of the Annual Meeting. CSC.5.1-CSC.05.7.

Mckinsey Global Institute (2017) Reinventing construction: a route to higher productivity, MGI: Mckinsey and Company, Research Report. Available at www.mckinsey.com/mgi accessed on 01.04.2017.

Rother, M and Shook, J. (1999) Learning to See: Value Stream Mapping to Create Value and Eliminate MUDA, The Lean Enterprise Institute, Brookline, Mass, USA.

Stringer, E.T. (1999) Action research, Thousand Oaks, CA: Sage Publications.

Tapping, D., Luyster, T., and Shuker, T (2002) Value Stream Management: Eight Steps to Planning, Mapping, and Sustaining Lean Improvements, Productivity Press, New York, NY, USA.

Technical Report 34 - Concrete Industrial Ground Floors, A guide to design and construction, The Concrete Society, Fourth Edition

Thomas, H.R. and Daily, J. (1983) Crew Performance Measurement via Activity Sampling. Journal of Construction Engineering and Management, ASCE, 109(3), 309-320.

Thomas, H.R., and Napolitan, C. (1999) Quantitative Effects of Construction Changes on Labor Productivity. Journal of Construction Engineering and Management, 124 (2), 290-296. 